Please do not remove this page

RMIT

UNIVERSITY

\title{
Fear, guilt and shame appeals in social marketing
}

Brennan, Linda-Marie; Binney, Wayne

https://researchrepository.rmit.edu.au/esploro/outputs/9921857849901341/filesAndLinks?institution=61RMIT_INST\&index=null

Brennan, L.-M., \& Binney, W. (2010). Fear, guilt and shame appeals in social marketing. Journal of Business Research, 63(2), 140-146. https://doi.org/10.1016/j.jbusres.2009.02.006

Document Version: Accepted Manuscript

Published Version: https://doi.org/10.1016/j.jbusres.2009.02.006

Repository homepage: https://researchrepository.rmit.edu.au

(C) 2009 Elsevier Inc. All rights reserved.

Downloaded On 2023/04/26 23:31:47 +1000

Please do not remove this page 
FEAR, GUILT, AND SHAME APPEALS IN SOCIAL MARKETING

\section{AUTHORS}

Linda Brennan*

Faculty of Business and Enterprise

Swinburne University of Technology,

John Street, Hawthorn Vic

Australia

Tel + 61392144861

Email: lbrennan@swin.edu.au

Wayne Binney

Faculty of Business \& Law

Victoria University of Technology,

Melbourne, Australia

Phone + 61399195207

Email Wayne.Binney@vu.edu.au

\section{ACKNOWLEDGEMENTS}

The authors would like to acknowledge the contribution of Sophie Alexiades and Zulekya Zevallos to the formative research stages and the assistance of the anonymous reviewers who provided advice and support in earlier versions of this paper.

October 2008 $63(2), 140-146$. 


\begin{abstract}
This paper presents results from a qualitative study of income support recipients with regard to how they feel about advertising which overtly appeals to their sense of fear, guilt and shame. The motivation of the study was to provide formative research for a social marketing campaign designed to increase compliance with income reporting requirements. This study shows that negative appeals with this group of people are more likely to invoke self-protection and inaction rather than an active response such as volunteering to comply. Social marketers need to consider the use fear, guilt and shame to gain voluntary compliance as the study suggests that there has been an overuse of these negative appeals. While more formative research is required, the future research direction aim would be to develop an instrument to measure the impact of shame on pro-social decision-making; particularly in the context of close social networks rather than the wider society.
\end{abstract}

\title{
KEY WORDS
}

Compliance, fear, guilt, shame advertising message appeals, social marketing 63(2), 140-146. 


\section{BACKGROUND}

Social marketing is used by many not for profit and government organizations to encourage behaviours which, while socially important, might not be germane to the personal motivations of the individual. Encouraging people to voluntarily comply with standards, norms or legal requirements, as individuals, is a necessary step in ensuring the wellbeing of the many. Individuals can be relied on to behave in their own best interests but not necessarily in the interests of others. This study was undertaken to assess the potential value of three common social marketing appeals fear, guilt, and shame - in terms of their capacity to induce compliant behaviours. The context of the study was income support recipients who often need to comply with reporting of extra income. The research took place prior to the development of campaign material relating to compliance and was used to inform campaign strategy.

Tables 1 and 2 outline the profile of participants and the types of income support they receive.

The purpose of this study was to ascertain which of the appeals might have the greater propensity to motivate such people to behave in a particular way; in this case, to adopt compliant behaviour. Whilst accepting that emotional situations are often imperfectly recalled, the research was designed to elicit people's recollections of campaigns that they believed were influential in motivating their personal behaviour(s) over time. The purpose was to ascertain if some emotional responses were more memorable or enduring than others and if people could associate selfreported memories of emotional response with subsequent 'compliant' outcomes (behavioural or otherwise). As a consequence, a qualitative study was conducted; primarily because the experimental designs usually associated with fear research (cf $63(2), 140-146$. 
Witte and Allen's (2000) meta-analysis of fear appeals in advertising) do not allow for a retrospective consideration of people's responses. Specific campaigns and their effectiveness or evaluation of the success of any particular campaign falls outside the scope of this research.

\section{OVERVIEW}

The use of social marketing is growing although it has been around as a concept for some time beginning with Kotler and Zaltman (1971). There is still some doubt amongst practitioners as to the efficacy of using commercial marketing principles in the promotion of public sector, government and social issues (Rothschild, 2005). Notwithstanding these concerns, the trend in the use of social marketing techniques is continuing apace especially for governments seeking to more efficiently deploy taxpayers’ resources. The need to encourage the public to voluntarily comply with requirements such as seat belts, drink driving, bushfire prevention, and so on, is an important component of public safety strategy development and the containment of subsequent costs such as health care. Studies of compliance motivations show that compliance requires regulation, a sense of duty and a concern for the thoughts of others (Tyler, 2000; May, 2004; 2005). Snitow and Brennan (2005) demonstrated that engendering compliance with social marketing calls-to-action was a multifaceted problem, comprising of an integrated system of legal and regulatory processes, enforcement, and public education (usually in the form of advertising).

\section{Selling compliance to the unwilling requires some innovative packaging}

Compliant behaviour is associated with conformity to institutional rules, and so, when people choose not to comply they stand answerable to consequences, which 
in an institutional or legal framework, could result in penalties such as fines, community service or legal action (cf. Harvey and McCrohan, 1988; May, 2005). Thus, the word voluntary must be used with some caution in the context of social marketing frameworks - is it truly voluntary if you must do it 'or else?' Nevertheless, social marketers encourage compliance by using message appeals (in this context not simply message framing) to link the socially desired behaviour to something that is of value to the individual. These appeals must be packaged or presented in a way that enables the individual to see the direct benefit (value) of their action. This value could be something which avoids negative consequences or which are positive incentives to behave in a certain way (Staub, 1997; Atkin, 2001). It could also be an empathetic motive rather than a personal one (Taute and McQuitty, 2004; Sturmer, Snyder and Omoto, 2005). Message appeals can be either positive or negative in nature, and they can additionally be divided into informational (or rational) appeals versus emotional appeals.

\section{Emotional appeals and social marketing}

Much recent research has been conducted into the influence of emotions in framing messages although not all of this is in the social marketing domain (Dillard and Peck, 2000; Frazer, Sheehan and Patti, 2002; Marchand and Filiatrault, 2002; James, Hasseldine, Hite and Toumi, 2003; Arthur and Quester, 2004; Berridge, 2004; Hastings, Stead and Webb, 2004; Maciejewski, 2004; Rossiter and Thornton, 2004; Chebat and Slusarczyk, 2005; Cotte, Coulter and Moore, 2005). Some authors distinguish between affect and emotions (Holbrook and Batra, 1987) and emotions and emotional feelings (Lazarus, 1991). Batra and Holbrook (1990) developed a typology of affective response categories with which to profile advertising. This typology incorporated fear and guilt but did not include shame. $63(2), 140-146$. 
The link between emotional arousal, attitude formation and behavioural compliance is still theoretically problematic with only tentative links drawn between attitudes and intent, and some still ambiguous findings relating to intent and eventual behaviour (Chandon, Morwitz and Reinartz, 2004). Notwithstanding these difficulties, social marketing campaigns often use emotional appeals in an attempt to encourage compliant behaviour from the public (cf. the many facets of road safety, cancer screening and HIV/AIDS campaigns). Negative emotional appeals are also regularly applied in consumer marketing to sell products which appeal to consumers' needs to conform to social norms (Bearden and Rose, 1990). Additionally, there is significant research which has studied the effectiveness of negative in comparison to positive emotional appeals (Wheatley and Oshikawa, 1970; Gardner and Wilheim, 1987; Homer and Yoon, 1992; Block and Keller, 1995; Frazer et al., 2002). Dillard and Peck (2000) showed that public service advertising effectiveness was influenced by fluctuating attitudes, changes in affective responses, and cognitive reactions for both positive and negative appeals.

\section{The use of negative appeals in social marketing and advertising}

Negative appeals are used to create an emotional imbalance which can be rectified by engaging in the featured (desired) behaviour, in this case regarded as compliant behaviour. It is hoped that by creating discomfort people will be motivated to act (or not) to decrease the feeling of discomfort. Negative emotions are known to cause psychic discomfort and are therefore a safe place to start when attempting to create appeals.

Fear appeals have been used for many years in advertising with varying degrees of success (Ray and Wilkie, 1970; Wheatley and Oshikawa, 1970; Rotfeld, 1988; Burnett and Lunsford, 1994; Latour and Rotfeld, 1997; Witte and Allen, 2000; 63(2), 140-146. 
Chandy, Tellis, Macinnis and Thaivanich, 2001; Laroche, Bergeron and BarbaroForleo, 2001; Hastings et al., 2004; Mowen, Harris and Bone, 2004; Rossiter and Thornton, 2004). However, Huhmann and Brotherton (1997) found differences in outcomes between fear, guilt, and shame.

Much research focuses on fear or threat appeals in advertising campaigns, and how coping responses may affect changes in attitude and, subsequently, behavioural changes (Kohn, Goodstadt, Cook, Sheppard and Chan, 1982; Maddux and Rogers, 1983; Tanner, Hunt and Eppright, 1991; Henthorne, Latour and Nataraajan, 1993; Schoenbachler and Whittler, 1996; Dillard and Peck, 2000; Witte and Allen, 2000; Arthur and Quester, 2004; Dillard and Anderson, 2004). The intensity of the appeal is also a consideration (Moore and Harris, 1996). Fear appeals can be subcategorized into physical and social fear appeals; physical fear appeals relate to threats which may afflict the body, and social fear appeals relate to threats connected with social acceptance (Schoenbachler and Whittler, 1996; Laroche et al., 2001). Lazarus (1991), while not assessing the impact of advertising per se, theorized that people react to threats by assessing the harm or benefit before developing an emotional response and subsequent physiological action. He posited that fear (generated as an outcome of a threat) was most likely to result in avoidance or escape. Others have found that empathy, as an outcome of negative emotions such as fear, increases the likelihood of helping others (Bagozzi and Moore, 1994; Vitaglione and Barnett, 2003). Such coping behaviours can be emotion-focused or problem-focused (Tamres, Janicki and Helgelson, 2002); and are dependent on self-efficacy, perceived severity of threat, and perceived probability of occurrence (Tanner et al., 1991).

Huhmann and Brotherton (1997) found that guilt appeals are as pervasive as fear appeals in the field of advertising. Others have found that guilt appeals are very $63(2), 140-146$. 
effective under certain (but different) circumstances (Coulter, Cotte and Moore, 1999; Cotte et al., 2005). There are many studies about guilt and its self-persuasive effects (Burnett and Lunsford, 1994; Coulter and Pinto, 1995; Huhmann and Brotherton, 1997; Bennett, 1998; Abe, 2004). However, it would seem that the relationship between guilt and fear may be studied at the expense of other negative emotions such as shame. Abe’s (2004) research does connect guilt and shame although not in relation to advertising appeals. Abe’s findings also showed that shame was more likely to elicit negative behaviours than guilt. In a further study of guilt, Bennett (1998) found that certain communications that are intended to invoke guilt might produce shameful responses among its target audience, and this ultimately results in negative consequences. Bennett found that guilt appeals are generally more likely to result in positive responses to advertisements and empathy. Conversely, shame appeals are unlikely to result in empathy and instead, they are more likely to result in negative attitudes. In order for a guilt appeal to be effective, Bennett advocates that potential shame-inducing properties need to be eliminated. Bennett's study did not find a correlation between guilt-intensive communications and psychological resistance, but other studies find that the degree of guilt evoked by an advertisement campaign could lead to anger and negative attitudes towards the corporate sponsor (Coulter and Pinto, 1995; Cotte, Coulter, and Moore, 2005).

\section{Negative appeals and compliance}

Shame has been studied in relation to tax compliance. For example, incorrect income reporting leads to significant financial loss for taxpayers (Braithwaite, 2002). Harvey and McCrohan's (1988) report on voluntary compliance of tax laws found that "appeals to conscience compared to sanction threats were more likely to result in increased reported income on tax returns” (p140). They argue that guilt appeals - that This paper is an early draft of a paper that later appears as: Brennan, L., \& Binney, W. (2010). Fear, guilt and shame appeals in social marketing. Journal of Business Research, $63(2), 140-146$. 
is, appeals to an individual's conscience - may be more effective than punitive threats and fear appeals. Additionally they argue that for voluntary compliance to occur, an action must be deemed important in wider society. In order for an advertisement to successfully communicate its message, the campaign should be promoted within a community framework, so that "the desired behaviour should result in peer approval rather than scorn” (p147). Tyler’s (2000) research illustrates the difficulties involved with implementing laws without willing and voluntary compliance and points out that threats and punishments do not work effectively.

Braithwaite’s (2002) review of several tax compliance studies led to a conclusion that shame occurs as a result of feeling guilty. Consequently, Braithwaite argues that a name and shame approach to tax compliance can successfully generate voluntary compliance among taxpayers. However, this would seem to be in contradiction to the findings of others who argue that guilt and shame are experienced differently and that these emotions can lead to different behaviours (Bennett, 1998; Chandy et al., 2001; Abe, 2004). Not enough is known about how shame influences behaviour or how it is felt.

How income support recipients react to the use of negative emotions such as fear, guilt, and shame in socially focussed communications is presented below.

\section{METHODOLOGY}

Data for this study were collected from 120 participants through a series of semi-structured in-depth interviews regarding their attitudes towards appeals in advertising and their self-reported emotional responses to these appeals. The latest Australian Census reported that 2.6-million Australians were receiving welfare support from the government. This figure corresponds to over 21-percent of the workforce-age population in Australia (Australian Bureau of Statistics, 2001). When This paper is an early draft of a paper that later appears as: Brennan, L., \& Binney, W. (2010). Fear, guilt and shame appeals in social marketing. Journal of Business Research, $63(2), 140-146$. 
income support recipients first sign up with the government body, they can nominate on their application forms that they are willing to participate in research. In 2006, there were almost three million Australians who receive welfare assistance, and 1.2million of these people agreed to be researched. From this pool of potential research participants, 270 people were initially contacted about the study by telephone, and 120 people agreed to be interviewed. The profile of those who agreed to participate is representative of the population of income support recipients (Australian Government, 2006).

\section{INSERT TABLE ONE ABOUT HERE \\ INSERT TABLE TWO ABOUT HERE}

The researchers were sensitive to the possibility that in asking participants to describe emotional reactions to advertising, they might inadvertently cue participants into providing socially acceptable or desirable responses (Strauss and Corbin, 1992). Thus, a proportion of the interview time was spent triangulating their answers (Denzin, 1970). The semi-structured interviews varied in length from half an hour to one and a half hours, depending on the communication needs of the participant and their willingness and ability to recall emotions. Questions were asked of participants regarding advertising (which could be any type of message format), that had evoked negative feelings. People were asked to describe the message and their response.

A research team of seven people conducted the interviews and analysis, including the two principal authors, one community worker and four postgraduate research students.

The interviews were transcribed and analysed using a hermeneutic method (Smith and Fletcher, 2004). This method of analysis requires that the analyst(s) reads the whole data set and develops a holistic picture of the data. The analyst then seeks This paper is an early draft of a paper that later appears as: Brennan, L., \& Binney, W. (2010). Fear, guilt and shame appeals in social marketing. Journal of Business Research, $63(2), 140-146$. 
to identify detailed themes and categories that emerge from the data. Subsequently, a search for any overarching themes or patterns, based on an understanding of the details of the text, is undertaken. At this stage of analysis, the analyst's views of the whole may change (Spiggle, 1994; Laverty, 2003). Finally, as the analysis identified areas of interest that were not evident in the beginning (as is often the case with qualitative research), a further literature review was undertaken to elucidate the themes identified (Wiklund, Lindholm and Lindströmb, 2002). At each stage of analysis, multiple researchers were involved.

\section{FINDINGS AND DISCUSSION}

Participants were asked how they felt about negative appeals in advertising, whether or not they recognised such appeals and if they felt they had responded behaviourally to any appeals which had been made. Participants were not prompted to discuss particular campaigns and independently nominated what they wanted to discuss. Most responses described were to public service or social advertising such as environmental awareness and charities.

\section{How people felt about the use of fear in advertising}

Of the negative emotions discussed, the participants were more likely to accurately recall advertisements that used fear as a major appeal, especially a fear of personal consequences, fear for others and fear of loss. As the participants described it, fear appeals in social marketing campaigns encouraged people to comply with rules and acceptable behaviour by scaring them about the potential legal, health and social risks associated with illegal, unhealthy or antisocial behaviour. However, fear was a strong word that the participants were hesitant about using. They frequently used words such as ‘worry', ‘concern’ or 'anxiety’, but it was clear that certain advertising aroused a fearful response in the participants. Fear was seen as an unhealthy reaction This paper is an early draft of a paper that later appears as: Brennan, L., \& Binney, W. (2010). Fear, guilt and shame appeals in social marketing. Journal of Business Research, $63(2), 140-146$. 
to advertising and something to be avoided. Of those that admitted to being fearful, the general response was to be afraid of dying or having a loved one die, and they were fearful of losing someone they loved through unsuccessful relationships. They were also afraid of not succeeding in life, although their definitions of success were sometimes different.

I am afraid of, in not too many years time, being unemployable, being destitute and being on the scrap heap of life, being regarded by my friends as a failure, becoming an outcast in society, having less self-esteem, being rejected by my family and becoming basically worthless. (Male, Unemployed 45-54)

Surprisingly, participants were more comfortable describing their responses in terms of shock or horror, as if these were more socially acceptable responses; potentially because these were seen to be reflexes rather than choices about an emotional response. The participants reported that for horror and shock to be influential it had to be realistic. That is, depictions of situations involving horror or shock were rejected if the scenario was not seen to be a realistic representation. Thus, the Grim Reaper campaigns, while successful in terms of generating recall and arousal, were not influential in terms of behaviour - 'that person was not 'me' and therefore I could safely ignore the message.’ The more confronting messages seemed to need a greater appeal to realism so that the participants were convinced of the idea that 'it could happen to me'. Realism in representation was crucial for messages to be taken seriously. As one participant said: 'People do respond [to fear appeals] as long as the message is pretty clear' (Male, Unemployed, 25-34 years). In order for the messages of fear campaigns to be clear, real situations and images had to be depicted 63(2), 140-146. 
in such a way that the viewer would see the depiction as 'necessarily ugly.' However, consistent with other studies, it was clear that some highly graphic and emotionally charged advertising resulted in emotional trauma leading to 'escape' from the message rather than engagement with, and intention to act as a result of, the message. Self-protection was most likely to be evoked in situations where there was the most empathy and close relationship with the issue at hand. As a consequence, the people most required to respond with action were those most likely to be attempting escape from the message.

I think over a certain amount of time they lose their effect to have a real emotional impact on you because you see so many of them, there are only so many times you can see a fictional [event], even if is based on truth before you just go - yeah, whatever. (Male, Unemployed 25-34)

Fear appeals that generated the most intense aversion were those that involved empathic responses (children, old people, similar others). When these appeals were coupled with horror or shock (as much pro-social advertising contains), and high levels of repetition, participants were likely to respond with anger towards the issue rather than fear, guilt or shame.

\section{Participants' responses to advertising which uses guilt}

The participants' discussion of marketing campaigns which appealed to feelings of guilt included advertisements that encouraged them to feel a sense of empathy, worry, angst or sorrow, and ultimately, they saw guilt appeals as encouraging voluntary compliance in regards to helping people who are less fortunate than themselves. The participants saw an important difference between fear and guilt appeals in social marketing campaigns. Whereas fear appeals are threatening, guilt appeals are aimed to encourage the public to consider their moral obligations towards This paper is an early draft of a paper that later appears as: $63(2), 140-146$. 
other people. As one participant succinctly put it: “...Guilt messages will have a better effect [than fear appeals] because it plays with your mind and your conscience” (Female, Unemployed, 45-54 years). The participants strongly associated guilt appeals with feelings of empathy, because they saw that guilt campaigns were designed to arouse sympathy for other people or a sense of affinity with a situation, such as campaigns about the environment, social justice and foreign aid agencies. The participants generally understood guilt appeals as those campaigns that encouraged them to think: 'I should do something to fix this problem'. The personalization of the appeal was an important factor in the development of these feelings. The participants accepted personal responsibility for the issue contained in the message before feeling guilty. If there was no personalization of the message, then people did not feel guilty although they could sense that the campaign was attempting to make them feel that way.

However, the participants felt that social marketing campaigns that appealed to guilt were increasingly pervasive: guilt appeals were everywhere they looked. Some participants felt guilt for not conforming to social norms and ideals, such as body image, consumerism and the pursuit of wealth. This guilt was exacerbated by their financial circumstances. Many felt guilt for being on the dole. Parents, in particular felt guilty that they could not afford to provide their children with more than the basics in life. Many parents felt guilty about not being good providers for their children.

When the kids go back to school every year, I have to borrow money to get them new shoes and uniforms. You can't send them to school looking like second-class citizens; they get teased by the other kids. (Female, Single parent, 25-34 years) $63(2), 140-146$. 
The only group who did not feel guilty about income support were the students who felt that their income support was an investment made by the government. There were many participants who suggested that they often felt guilt when watching global charity advertisements for World Vision and Oxfam because they felt fortunate in comparison to the poverty in other countries whose governments are unable to offer social welfare. As the following statement shows, some participants felt that the media encourages people to feel guilty about every aspect of their lives:

Going to the gym and not eating healthy. Most people feel guilty in the same way because society says you should be home at night with your children and at the gym and that you should be a size 8 and not a 12. It's what the media tell you should do. (Female, Partnered Parent, 25-34 years)

Many reported that they were learning to resist feeling guilty because of the sheer volume of messages designed to create a sense of guilt. Overall, the participants felt negatively towards marketing campaigns that used guilt appeals, even when they recognized that these campaigns were for a 'good cause. Due to the multitude of worthy causes and their own financial position as welfare recipients, the participants felt a sense of helplessness to help others.

Guilt messages usually ask for money and most people don’t have the money to donate and those that do that kind of thing make me feel guilty about it but I don’t really know what I can do about it right now. (Female, Unemployed, 25-34 years) $63(2), 140-146$. 
It would appear that there was a level of guilt that the participants would accept before they invoked a self-protection mechanism to help them ignore messages appealing to their sense of guilt.

\section{Feeling guilty is a personal choice}

Feeling guilty was associated with a clearly understood moral obligation towards others, but because guilt was experienced privately and subjectively, guilt appeals could be ignored:

Guilt is a very personal thing. I think people feel guilty about many different things. Something that makes me feel guilty would not necessarily make you feel guilty and vice versa. (Male, Unemployed, 25-34 years)

Because the participants saw guilt as 'a very personal thing' they could opt out of complying with a call to action in social marketing campaigns because they could alleviate their sense of guilt or justify their non-compliance in different ways. For example, one person may feel guilty about the environment and not recycling, but they may not feel guilty about world poverty. In another example, one participant recognized the guilt appeal in a recent campaign about water shortages in his local area, but he continued to hose down his driveway because he lived on his own and he ‘didn’t use much water’ (Male, 45-54, Unemployed).

Ultimately, the participants did not feel that guilt appeals had positive outcomes: "I think that guilt is a destructive emotion, so from a personal point of view that would not work [to motivate me]” (Female, Partnered Parent, 25-34). The participants suggested that guilt messages which helped them understand how their small and individual efforts could assist in solving large social problems would be more useful than guilt messages on their own. $63(2), 140-146$. 
Everyone can make a difference. You need to provide avenues to show that you can help. Cause and effect style ads could work. There are pathways, it’s not all hopeless. (Male Unemployed 35-44 years)

\section{Shaming results in an emotional backlash}

The participants defined shame as an emotion that individuals experience when other people who are significant to them become aware of their socially unacceptable behaviour. As they saw it, individuals do not feel ashamed unless they care what others think about them. The closer you are to the people who see your shame, the more likely you are to feel shame if you do something against the reference groups’ principles. This participant explains:

I am sensitive to what people think but it all depends on who is thinking what. Some of them I couldn’t care. Only if I admired their opinions and if it was somebody I have a high regard for, I would care. (Female, Aged, 75+)

Drinking and driving is very irresponsible and dangerous and I guess it is supposed to shame you into not doing it really, I mean that's the message behind it really isn't it, the shame factor, if you drink and drive all your friends will shun you (Female, Partnered Parent, 35-44)

As the participants described it, guilt and shame appeals both carried messages about the moral consequences of one's action and 'doing the right thing', such as avoiding killing another human being through not drink driving. The participants saw a connection between the two emotions: shame is related to guilt in the way that a person must first feel guilty in order to feel ashamed. That is, in order to feel guilt and shame, you have to feel as if you have done something wrong (or that you are not doing enough to do the right thing), or you have to recognise that you are not doing This paper is an early draft of a paper that later appears as: Brennan, L., \& Binney, W. (2010). Fear, guilt and shame appeals in social marketing. Journal of Business Research, 63(2), 140-146. 
enough to help other people. This guilt must be publicly demonstrated to others to be considered shaming. The participants saw that feeling guilty was associated with a clearly understood call to action, but was subjectively felt. For this reason, guilt was more self-referencing than shame. Conversely, shame carried a clear set of social consequences that were defined as public. As this participant said: “Guilt is a personal feeling; shame is something you feel because you are not as good as the person next to you” (Female, Partnered Parent and Disabled, 35-44 years).

Someone can feel guilty and not feel as if they need to do something as a response to the guilt; however, the participants were motivated to alleviate their shame by engaging in a positive or reparative action. Participants were unlikely to feel shamed unless the people aware of their action were their close personal friends or family members.

Guilt means that you have done something wrong, where shame means that you didn’t do anything to prevent it. (Male, Aged, 75+ years)

When you're ashamed of something it's a totally different feeling, you feel totally different. When you feel guilty about something usually you rectify the situation. If you do something you felt guilty about not doing or confess you usually feel better, but when you're ashamed of something even if you do try and rectify the situation - you still feel really bad about it. (Female, Unemployed, 15-24 years)

Shame was related to embarrassment, foolishness and humiliation more than guilt, which would suggest that shame has deeper effects than guilt due to the likelihood of social exposure. This was because the participants felt that shame was more likely to arise in situations wherein people became aware that you had done 63(2), 140-146. 
something wrong. As a participant said: "Guilt is something you have for a day or two and then you forget about it; but if you're truly ashamed about something it's there longer” (Female, Student, 35-44 years). Many participants suggested that shame was more 'debilitating' than guilt. This sense came about because of the social consequences attached to shame. The effects of being shamed would last longer and take more effort to alleviate.

Shame appeals were generally thought of in a negative light and as an ineffective method for motivating people to do the right thing. They did not believe that shame appeals evoke the same 'escape’ reaction as marketing messages that use fear appeals, but the consequences of public shaming were seen to be unacceptable. The participants typically said things like: 'everyone has a right to keep things to themselves; especially if they made a mistake'. Several participants suggested that it was better to try to make someone proud for doing something, rather than make them feel ashamed for not doing something properly. They felt that shame would lead to depression and contribute to a sense of hopelessness and therefore would not be an appeal that should be used - even if it could be used effectively.

Messages that shame people seem a bit sort of totalitarian, a bit Big Brotherish. Messages that show you what you might do that might be foolish and show you how to do it better I think they're fine. (Male, Unemployed, 25-34 years)

I think there's better ways to persuade people to do things than making them feel foolish or ashamed. (Female, Unemployed, 15-24 years)

In order to protect themselves from feeling shamed about their illegal or inappropriate behaviour depicted in social marketing campaigns, the participants $63(2), 140-146$. 
would justify their behaviour in terms of acceptability. For example, speeding is acceptable if you do it 'safely'; getting paid untaxed cash amounts for working while receiving unemployment welfare support is acceptable because 'everyone does it'. Acceptability was seen within a relatively narrow social context and not in terms of the wider society.

\section{People reach a point of emotional saturation with negative appeals}

The participants described feeling saturated by negative emotional appeals. Many felt that even when they take notice of marketing campaigns, they would 'switch off' from the message because of the negativity depicted within the message and any subsequent call to action. Advertising that was designed to generate voluntary compliance, therefore, had great obstacles in reaching their target audience, especially in regards to overcoming apathy. As one participant said, "We're in a society where anything goes, [and] there are so many [ads] out there that we couldn't care less about them” (Female, Aged, 65-74 years). This study found that positive emotion appeals in social marketing campaigns had a greater potential to not only 'get people talking' about an advertisement (as was the case with the fear appeals), but also in motivating people to act upon the call for voluntary compliance. For example, humour was often used as an example of marketing communication which motivated people to act.

The 'slip, slop slap’ ads [anti- skin cancer campaign] were good. They were light hearted; showed people playing up in cartoons and let us know what we should be doing. They didn’t make me feel bad about being out in the sun but they did let me know I should take care of myself and the kids. I certainly started thinking about even though they weren’t very 'real.’ I know I started to wear hats about then (Male, Unemployed, 55-64 years) $63(2), 140-146$. 
It is important to note that compliance, as a word, was problematic in this study. Participants universally suggested that on becoming aware that they were being asked to ‘comply' with something would consider such an appeal as force or coercion (and therefore not voluntary). However, there were calls to action which had been influential. This was especially the case for campaigns that demonstrated how one individual 'can make a difference' and those campaigns which demonstrated the personal rewards - rather than punishments - of voluntary compliance.

\section{CONCLUSION}

This study shows that people are responding to emotional appeals in pro-social advertising and that this response mirrors the process defined by Lazarus (1991) of Threat>Appraisal>Coping behaviour. However, the method of coping adopted is not problem-oriented and this results in anger, retreat and despondency as the felt emotional responses. These emotions are demonstrated (by others) to be the antithesis of useful when attempting to motivate compliance (cf. Bagozzi and Moore, 1994); although empathetic anger is an important element in eliciting helping behaviours (Vitaglione and Barnett, 2003). Indeed, many of the seemingly maladaptive responses may be associated with Staub’s (1997) concept of 'altruism born of suffering.' The repertoire of coping strategies (de Ridder and Kerssens, 2003) would seem to be limited by the constrained social circumstances of the group. With this group of people, more fear may not be better although this is converse to others' findings (cf. Witte and Allen, 2000).

Furthermore, while fear and guilt are used extensively in advertising, the emotional response educed within these participants is not the one framed by the advertiser. The variety of emotional responses expressed varies from passive helplessness to angry activism. Thus, the existing research stream into message This paper is an early draft of a paper that later appears as: Brennan, L., \& Binney, W. (2010). Fear, guilt and shame appeals in social marketing. Journal of Business Research, $63(2), 140-146$. 
framing might need to consider an alternative array of responses; some of which are emotions in the defined sense (Batra and Holbrook, 1990) and some of which are illdefined but just as felt.

This research explored the use of fear, guilt and shame in a qualitative sense. While there is a significant amount of research supporting theory development in the fear and guilt domain, these results show that theory of shame in advertising is under developed. Future research could investigate concepts of shame and how it might be usefully deployed within normal populations. Any future affective typologies could include the concept of shame. While more formative research is required, the future research direction aim would be to develop an instrument to measure the impact of shame on pro-social decision-making; particularly in the context of social networks rather than the wider society. It is not known if these responses to message appeals are related to the social milieu in which the participants find themselves or if there is potential for a wider application. Furthermore, this research illustrates that concepts of shame are related to the specific social group of the participant. It would appear that shame is not felt unless it engendered within the group context.

The use of fear appeals has been demonstrably successful in other studies. However, the sheer number of emotive messages being sent limits the emotional energy able to be invested by an individual. In this sample, the emotional energy required to feel fearful or guilty is already attenuated. While there is a focus on television advertising in these responses, the most enduring campaigns in this study are those that have been integrated across a variety of media. Negative campaigns aimed at generating enduring behavioural change need to consider that people develop very sophisticated (but maladaptive) coping strategies to ensure that their core emotional and psychological well being is not influenced. As a consequence, $63(2), 140-146$. 
advertisers could embed suggested coping strategies within the advertising that linked the desired behavioural outcome to socially positive consequences.

Encouraging voluntary compliance with socially valuable (but not always individually valued) ideals requires a consideration of how people can be motivated to act (or not). However, this study shows that, for income support recipients at least, overt use of compliance strategies is likely to have the opposite effect from that intended. Fear, guilt, and shame have been shown to be differentially motivating; with an overuse of fear messages resulting in fight more often than not, and shame resulting in flight from the message. Guilt can be motivating but only when accompanied by some hope that individual action is both needed and capable of making the requisite social change. The participants in this study were overwhelmed by guilt, and messages invoking guilt were likely to invoke self-protection rather than encourage action. This study shows that for social marketing to be successful, the size and scope of the problem people are being called upon to resolve with their actions must also be within the capacity of individual achievement. Much advertising, in delineating the international or global scope of the problem(s), decreases the selfefficacy of the individual and therefore decreases the likelihood of action. Furthermore, the indiscriminate use of negative appeals by many marketers in the social and consumer domains is resulting in emotional burn-out and therefore a decreased likelihood of acceptance of any messages - even the important ones. 63(2), 140-146. 


\section{References}

Abe Jo Ann. Shame, Guilt and Personality Judgment. Journal of Research in Personality 2004; 38 (2): 85-104.

Arthur Damien, Quester Pascale. Who's Afraid of That Ad? Applying Segmentation to the Protection Motivation Model. Psychology \& Marketing 2004; 21 (9): 671-696.

Atkin Charles K. Theory and Principles of Media Health Campaigns. In: Ronald E Rice, Charles Atkin editors. Public Communications Campaigns, Thousand Oaks Ca: Sage, 2001. 49-68.

Australian Bureau of Statistics. Community Services, Australia, 1999-2000. Canberra ACT, 2001.

Australian Government. Income support customers: A statistical overview 2002.

Canberra ACT: Australian Government: Department of Families, Community Services and Indigenous Affairs, 2006. pp. 89.

Bagozzi Richard P, Moore David J. Public service advertisements: Emotions and empathy guide prosocial behavior. Journal of Marketing 1994; 58 (1): 56-70.

Batra Rajeev, Holbrook Morris B. Developing a typology of affective responses to advertising. Psychology \& Marketing 1990; 7 (1 Spring): 11-25.

Bearden William O, Rose Randall L. Attention to social comparison information: An individual difference factor affecting consumer conformity. Journal of Consumer Research 1990; 16 (March): 461-471.

Bennett Roger. Shame, guilt and responses to non-profit and public sector ads. International Journal of Advertising 1998; 17 (4): 483-499.

Berridge Kent C. Motivation concepts in behavioural neuroscience. Physiology \& Behaviour 2004; 81: 170-209. $63(2), 140-146$. 
Block Lauren G, Keller Anand Punam. When to Accentuate the Negative: The Effects of Perceived Efficacy and Message Framing on Intentions to Perform a Health-Related Behaviour. Journal of Marketing Research 1995; 32 (2): 192204.

Braithwaite Valerie. The centre for tax system integrity 2002 report. Canberra ACT: The Centre for Tax System Integrity, 2002.

Brennan Linda, Snitow Samantha. Social Marketing Success: A Case Study of Collaboration and Cooperation Between Enforcement, Legislation and Advertising Initiatives. $2^{\text {nd }}$ Australasian Nonprofit and Social Marketing Conference: At the threshold: Challenges and developments in social, sport and arts marketing 2005; Stonnington Campus, Deakin University.

Burnett Melissa S, Lunsford Dale A. Conceptualizing guilt in the consumer decisionmaking process. Journal of Consumer Marketing 1994; 11 (3): 33-43.

Chandon Pierre, Morwitz Vicki G, Reinartz Werner J. The Short- and Long-Term Effects of Measuring Intent to Repurchase. Journal of Consumer Research 2004; 31 (3): 566-572.

Chandy Rajesh K, Tellis Gerard J, Macinnis Deborah J, Thaivanich Pattana. What to say when: Advertising appeals in evolving markets. What to say when: Advertising appeals in evolving markets, working paper series. \#01-103.: Marketing Science Institute, 2001.

Chebat Jean-Charles, Slusarczyk Witold. How emotions mediate the effects of perceived justice on loyalty in service recovery situations: an empirical study. Journal of Business Research 2005; 58 (5): 664-673. $63(2), 140-146$. 
Cotte June, Coulter Robin A, Moore Melissa. Enhancing or disrupting guilt: The role of ad credibility and perceived manipulative intent. Journal of Business Research 2005; 58 (3 March): 361-368.

Coulter Robin Higie, Cotte June, Moore Melissa Lunt. Believe It or Not: Persuasion, Manipulation and Credibility of Guilt Appeals. Advances in Consumer Research 199926 (1): 288-295.

Coulter Robin Higie, Pinto Mary Beth. Guilt appeals in advertising: What are their effects? Journal of Applied Psychology 1995; 80 (5): 697-705.

de Ridder Denise, Kerssens Jan. Owing to the force of circumstances? The impact of situational features and personal characteristics on coping patterns across situations. Psychology and Health 2003; 18 (2): 217-236.

Denzin Norman. Triangulation, Sociological methods. Aldine. 1970 471-475

Dillard James Price, Anderson Jason W. The role of fear in persuasion. Psychology \& Marketing 2004; 21 (11): 909-926.

Dillard James Price, Peck Eugenia. Affect and persuasion: Emotional responses to public service announcements. Communication Research 2000; 27 (4): 461495.

Frazer Charles F, Sheehan Kim Bartel , Patti Charles H. Advertising strategy and effective advertising: comparing the USA and Australia. Journal of Marketing Communications 2002; 8 (3, September): 149-164.

Gardner Meryl Paula, Wilheim Frederick O Jr. Consumer responses to ads with positive vs. negative appeals: Some mediating effects of context-induced mood and congruency between context and ad. Current Issues \& Research in Advertising 1987; 10 (1): 81-98. $63(2), 140-146$. 
Harvey James W, McCrohan Kevin F. Is there a better way of improving compliance with the tax laws? Insights from the philanthropic literature. Journal of Public Policy \& Marketing 1988; 7 (1): 138-151.

Hastings Gerard, Stead Martine, Webb John. Fear appeals in social marketing: strategic and ethical reasons for concern. Psychology \& Marketing 2004; 21 (11): 961-986.

Henthorne Tony L , Latour Michael S , Nataraajan Rajan. Fear appeals in print advertising: An analysis of arousal and ad response. Journal of Advertising 1993; 22 (2): 59-70.

Holbrook Morris B, Batra Rajeev. Assessing the role of emotions as mediators of consumer responses to advertising. Journal of Consumer Research 1987; 14 (December): 404-420.

Homer P M , Yoon S. Message framing and the interrelationships among ad-based feelings, affect, and cognition. Journal of Advertising 1992; 21 (1): 19-34. Huhmann Bruce A , Brotherton Timothy P. A content analysis of guilt appeals in popular magazine advertisements. Journal of Advertising 1997; 26 (2): 35-46.

James Simon , Hasseldine John, Hite Peggy, Toumi Peggy. Tax compliance policy: An international comparison and new evidence on normative appeals and auditing (Draft Manuscript). ERSC Future Governance Workshop 2003; Centre for Policy Studies, Central European University, Budapest.

Kohn Paul M, Goodstadt Michael S, Cook Gaynoll M, Sheppard Margaret, Chan Godwin. Ineffectiveness of threat appeals about drinking and driving. Accident Analysis \& Prevention 1982; 14 (6): 457-464.

Kotler P, Zaltman G. Social Marketing: An Approach to Planned Social Change. Journal of Marketing 1971; 35 (July): 3-12. 63(2), 140-146. 
Laroche Michel, Toffoli Roy, Zhang Quihong, Pons Frank. A cross-cultural study of the persuasive effect of fear appeal messages in cigarette advertising: China and Canada. International Journal of Advertising 2001; 20 (3): 297-317.

Latour Michael S, Rotfeld Herbert J. There are threat and (maybe) fear-caused arousal: Theory and confusions of appeals to fear and fear arousal itself. Journal of Advertising 1997; 26 (3): 45-60.

Laverty Susann M. Hermeneutic Phenomenology and Phenomenology: A

Comparison of Historical and Methodological Considerations. International Journal of Qualitative Methods 2003; 2 (3 September): Article 3. Retrieved 3rd December 2004 from

http://www.ualberta.ca/ iiqm/backissues/2002_2003final/pdf/laverty.pdf.

Lazarus Richard S. Progress on a Cognitive-Motivational-Relational Theory of

Emotion. American Psychologist 1991; 48 (8 August): 819-834.

Maciejewski Jeffrey I. Is the Use of Sexual and Fear Appeals Ethical? A Moral Evaluation By Generation Y College Students. Journal of Current Issues \& Research in Advertising 2004; 26 (2): 97-105.

Maddux James E, Rogers Ronald W. Protection motivation and self-efficacy: A revised theory of fear appeals and attitude change. Journal of Experimental Social Psychology 1983; 19 (5, September): 469-479.

Marchand June, Filiatrault Pierre. AIDS prevention advertising: Different message strategies for different communication objectives. International Journal of Nonprofit and Voluntary Sector Marketing 2002; 7 (3): 271-288.

May Peter J. Compliance Motivations: Affirmative and Negative Bases. Law \& Society Review 2004; 38 (1): 41-68. $63(2), 140-146$. 
May Peter J. Regulation and Compliance Motivations: Examining Different Approaches. Public Administration Review 2005; 65 (1): 31-44.

Moore David J, Harris William D. Affect intensity and the consumer's attitude toward high impact emotional advertising appeals. Journal of Advertising 1996; XXV (2 Summer): 37-50.

Mowen John C, Harris Eric G, Bone Stirling A. Personality traits and fear response to print advertisements: Theory and an empirical study. Psychology \& Marketing 2004; 21 (11): 927-943.

Ray ML, Wilkie WL. Fear: The potential of an appeal neglected by marketing. Journal of Marketing 1970; 34 (January): 54-62.

Rossiter John R, Thornton Jennifer. Fear-pattern analysis supports the fear-drive model for antispeeding road-safety TV ads. Psychology \& Marketing 2004; 21 (11): 945-960.

Rotfeld Herbert J. Fear Appeals and Persuasion: Assumptions and Errors in Advertising Research. Current Issues and Research in Advertising 1988; 11 (1): 21-40.

Rothschild Michael. The potential role of social marketing in the future of public health behavior management. $2^{\text {nd }}$ Australasian Nonprofit and Social Marketing Conference: At the threshold: Challenges and developments in social, sport and arts marketing 2005; Stonnington Campus, Deakin University.

Schoenbachler Denise D , Whittler Tommy E. Adolescent processing of social and physical threat communications. Journal of Advertising 1996; 25 (4): 37-55.

Smith David VL, Fletcher John H. The Art \& Science of interpreting market research. West Sussex, UK: John Wiley \& Sons, 2004. $63(2), 140-146$. 
Spiggle Susan. Analysis and interpretation of qualitative data in consumer research. Journal of Consumer Research 1994; 21 (December): 491-503.

Staub Ervin. The roots of goodness: the fulfillment of basic human needs and the development of caring, helping and non-aggression, inclusive caring, moral courage, active bystandership, and altruism born of suffering. Gender and Motivation 1997; Nebraska Symposium on Motivation; pp 45.

Strauss A L, Corbin J. Basics of Qualitative Data Research: Grounded Theory Procedures and Techniques. Newbury Park CA: Sage, 1992.

Sturmer Stefan, Snyder Mark, Omoto Allen M. Prosocial Emotions and Helping : The Moderating Role of Group Membership. Journal of Personality and Social Psychology 2005; 88 (3): 532-546.

Tamres Lisa, Janicki Denise, Helgelson Vicki S. Sex differences in coping behavior: A meta-analytic review and examination of relative coping. Personality and Social Psychology Review 2002; 6 (1): 2-30.

Tanner John F Jnr, Hunt James B, Eppright David R. The Protection Motivation Model: A normative model of fear appeals. Journal of Marketing 1991; 55 (July): 36-45.

Taute Harry, McQuitty Shaun. Feeling good! Doing good! An exploratory look at the impulsive purchase of the social good. Journal of Marketing Theory and Practice 2004 (Spring): 16-27.

Tyler Tom R. Multiculturalism and the Willingness of Citizens to Defer to Law and to Legal Authorities. Law \& Social Inquiry 2000; 25 (4): 983-1019. Vitaglione Guy D, Barnett Mark A. Assessing a new dimension of empathy: Empathetic anger as a predictor of helping and punishing desires. Motivation and Emotion 2003; 27 (4): 301-325. $63(2), 140-146$. 
Wheatley John J, Oshikawa Sadaomi. The relationship between anxiety and positive and negative advertising appeals. Journal of Marketing Research 1970; VII: 85-89.

Wiklund Lena, Lindholm Lisbet, Lindströmb Unni Å. Hermeneutics and narration: a way to deal with qualitative data. Nursing Inquiry 2002; 9 (2): 114-125.

Witte Kim, Allen Mike. A meta-analysis of fear appeals: Implications for effective public health campaigns. Health Education \& Behavior 2000; 27 (5 October): 591-615. 
Table 1 Interview participants and location*

\begin{tabular}{lcccccc}
\hline & DSP & AUS & NSA & AGE & PPS & PPP \\
ACT & & & & 2 & & \\
NSW & 2 & 6 & 9 & 3 & 2 & 2 \\
Queensland & 2 & 10 & 3 & 7 & 3 & 3 \\
Victoria & 10 & 8 & 18 & 9 & 11 & 7 \\
\hline Total & $\mathbf{1 4}$ & $\mathbf{2 4}$ & $\mathbf{3 0}$ & $\mathbf{2 1}$ & $\mathbf{1 6}$ & $\mathbf{1 2}$ \\
\hline Rural & 5 & 6 & 28 & 16 & 12 & 9 \\
Metropolitan & 9 & 18 & 2 & 5 & 4 & 3 \\
\hline
\end{tabular}

DSP $=$ Disability support pension, AUS $=$ Austudy (studying), NSA $=$ Newstart allowance (unemployed) AGE $=$ Aged pension, $\mathbf{P P S}=$ Sole parents pension, $\mathbf{P P P}=$ Partnered parenting pension. Not all income support recipients are wholly supported by government allowances. Many work at least part time and in the case of some families even full time workers can fall below the minimum wage and therefore be entitled to government support.

Table 2: Gender and age of respondents*

\begin{tabular}{lccc}
\hline Age range & Male & Female & Total \\
$\mathbf{1 5}$ to $\mathbf{2 4}$ & 9 & 7 & 16 \\
$\mathbf{2 5}$ to $\mathbf{3 4}$ & 20 & 13 & 33 \\
$\mathbf{3 5}$ to $\mathbf{4 4}$ & 7 & 16 & 23 \\
$\mathbf{4 5}$ to $\mathbf{5 4}$ & 6 & 10 & 16 \\
$\mathbf{5 5}$ to $\mathbf{6 4}$ & 5 & 8 & 13 \\
$\mathbf{6 5}$ to $\mathbf{7 4}$ & 6 & 5 & 11 \\
Over $\mathbf{7 5}$ & 2 & 2 & 4 \\
Total & $\mathbf{5 5}$ & $\mathbf{6 1}$ & $\mathbf{1 1 6}$ \\
\hline
\end{tabular}

* Note these figures represent data where provided by the participants (there are 120 responses but not all people willingly answered type of support or age category) 